Portland State University

PDXScholar

\title{
Adapting RealTime Physics for Distance Learning with the IOLab
}

\author{
Erik Bodegom \\ Portland State University, bodegom@pdx.edu \\ Erik Jensen \\ Chemeketa Community College \\ David Sokoloff \\ University of Oregon
}

Follow this and additional works at: https://pdxscholar.library.pdx.edu/phy_fac

Part of the Physics Commons

Let us know how access to this document benefits you.

\section{Citation Details}

Published as Bodegom, E., Jensen, E., \& Sokoloff, D. (2019). Adapting RealTime Physics for Distance Learning with the IOLab. Physics Teacher, 57(6), 382-386.

This Post-Print is brought to you for free and open access. It has been accepted for inclusion in Physics Faculty Publications and Presentations by an authorized administrator of PDXScholar. Please contact us if we can make this document more accessible: pdxscholar@pdx.edu. 


\section{Adapting RealTime Physicsfor Distance Learning with the IOLab}

The IOLab is a versatile and inexpensive data acquisition device in a cart that can roll on its three wheels. It has numerous sensors for a variety of physical quantities. We adapted RealTime Physics, Module 1: Mechanics active learning labs for use with the IOLab. We tested these labs both on campus and with distance learners at Portland State University and Chemeketa Community College for three years, consistently obtaining significant conceptual learning gains on the Force and Motion Conceptual Evaluation (FMCE). Student attitudes towards the labs, the device, and distance learning-as measured by post-course evaluations-were generally very positive.

\section{Introduction}

Distance higher-education continues to grow ${ }^{1}$ in spite of both flat enrollment in highereducation overall ${ }^{2}$ and scandals ${ }^{3}$ at for-profit universities. But science fields, especially physics, have been slow to adapt to demand ${ }^{4}$, often based on the perceived difficulty of delivering labs effectively and safely at a distance.

The 2014 AAPT Recommendations for the Undergraduate Physics Laboratory Curriculum ${ }^{5}$ include "constructing knowledge" as a desirable learning outcome. In spite of the development of online simulations and activities, it is still important for distance-learning students to have an authentic laboratory experience in which they physically manipulate objects and actively use their observations to create or modify their conceptual models of the physical world. Recent advances in low-cost sensors and data analysis software make it feasible to offer physics labs in the context of an online or distance course.

But the solution to this problem requires more than technology. Recent research suggests that "traditional" lab experiences do not meaningfully impact student learning. ${ }^{6,7}$ It should be noted, however, that this research did not include studio courses, or courses implementing RealTime Physics $(R T P)^{8}$ as their lab component. In fact, it has been well documented that RTP — a research-validated, active learning lab curriculum — can guide students to consider and modify their conceptual understandings. ${ }^{8}$ While RTP has been demonstrated to be effective in-class, it cannot 
easily be used in distance-learning due to the cost, size, and complexity of the computer-based lab equipment. For this project we proposed the combination of the inexpensive IOLab device with the RTP curriculum as a solution to the need for research-validated, distance-learning mechanics labs.

\section{The IOLab and IOLab software}

The low cost (\$120) and versatility of the IOLab ${ }^{9}$ make it attractive for distance-learning applications. It is a versatile data acquisition device that is self-contained in a cart (see Figure 1). Its motion on its wheels is detected by an optical encoder, allowing measurement of motion quantities. It has numerous sensors for a variety of physical quantities, including a force sensor. This makes it ideal for examining its motion under a variety of conditions, and for exploring Newton's laws of motion. Figure 2 shows graphs generated by the IOLab rolling up and back down an inclined ramp.

The basic IOLab software-that is free with the hardware-allows users to choose both the sensors to be activated and features of the graphs to be collected (such as axis limits). It also allows simple data analysis such as statistics and curve fitting. Lesson Player, a component of the IOLab software, allows these settings to be selected in advance of data collection (although students can still change them after data collection if this displays the data more clearly). With Lesson Player, instructions, questions, and answer boxes are displayed on one half of the screen while collected graphs are displayed on the other half in real time (see Figure 3). Also, with Lesson Player, students can complete and submit their work electronically. These features are all wellsuited for our adaptation of RTP for distance-learning. Other "smart carts" have become available during the timeline of this project. ${ }^{10}$ it was not within the scope of this project to

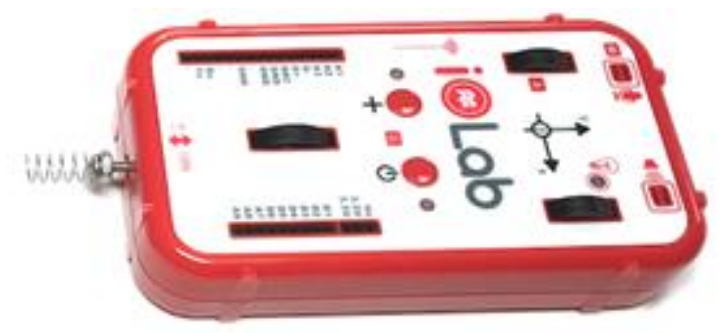

Figure 1. The IOLab, an inexpensive data acquisition device in a cart that can roll on its three wheels. 
compare the capabilities of these, and they are significantly more expensive than the IOLab. The PocketLab ${ }^{11}$, although quite capable, is also significantly more expensive than IOLab and does not include an encoder or force sensor.

\section{RealTime Physics pedagogy}

Beginning in 1992 a set of RTP labs was developed with funding from the National Science Foundation. Four lab guides (modules) are currently published by John Wiley and Sons. ${ }^{12}$ Each lab guide includes activities for use in a series of related lab sessions that span an entire quarter or semester for the lab accompanying either the calculusbased or algebra-based introductory physics course. Lab activities and homework assignments are integrated so that they build on learning that has occurred during the previous lab session and prepare students for activities in the next session. The major goals of the RTP curriculum are to help students: (1) acquire an understanding of a set of related physics concepts; (2) experience the physical world directly by using computer-based tools for real-time data collection, display and analysis, (3) develop traditional laboratory skills; and (4) master topics covered in lectures and readings using a combination of conceptual activities and quantitative experiments.

In order to achieve these goals, a set of design principles was developed for the laboratory guides. Lab activities (1) are sequenced and build on each other, (2) invite students to construct physical models based on their observations, (3) incorporate a learning cycle of prediction, observation, and comparison to help students to modify their common, naive conceptions, and to understand powerful general physics principles, (4) provide opportunities for students to discuss ideas and findings in small groups of 2-4, (5) include a pre-lab assignment to prepare for lab and a homework assignment designed to reinforce critical concepts and skills.

\section{The IOlab Distance Learning Laboratory Project}

Starting in 2015 , with support from the National Science Foundation ${ }^{13}$, we developed a series of mechanics labs for use with the IOLab in distance-learning environments. 
These labs are mostly based on RTP, as adapted for the particular characteristics of the IOLab and software.

A recent paper has documented that physics education research is typically done with students who are "better prepared mathematically and are less diverse than the overall physics student population." 14 We avoided this issue by testing the labs we developed for IOLab at Portland State University (PSU), an urban university with an 89\% acceptance rate ${ }^{15}$, and at Chemeketa, an open-enrollment community college in the process of obtaining federal designation as an Hispanic-Serving Institution. ${ }^{16}$

At PSU, all students were enrolled in a campus-based traditional lecture (either calculus or algebra-based) and experienced our labs either on campus (in a normal laboratory room) or in distance-learning mode. At Chemeketa, all students were enrolled in an active-learning, ${ }^{17}$ algebra-based course. Chemeketa students were either entirely campus-based or entirely in distance-learning mode. ${ }^{18}$ We loaned an IOLab to each distance-learning student. While the IOLab includes a few accessories from the manufacturer such as springs and hooks, we provided an additional kit with a protractor, a bouncy ball, clay, fishing line, weights, and a few other items for an additional cost to us of about $\$ 10$ per student.

Table 1 lists the titles of the final versions of the nine labs that we developed. (Note that Lab 8 also makes use of video analysis ${ }^{19}$ to examine the projectile motion of a thrown ball.) Control groups at both institutions completed traditional labs: on-campus at PSU and in distance-learning mode at Chemeketa with traditional lab kits. ${ }^{20}$

As part of the project, we tested IOLab active learning labs during five rounds at each institution. ${ }^{21}$ Each of these rounds afforded us opportunities to observe campus-based students in class as they worked through the labs, to examine the graphs all groups collected and the lab sheets they turned it, and to assess their understanding of mechanics concepts. This was an iterative process during which we revised the labs, hardware, and software according to what we learned. Among the lessons we learned from this process are: 
- The lack of bearings in the low-cost wheels of the IOLab results in significant friction. For example, the acceleration of the IOLab while rolling up an inclined ramp is noticeably different from that rolling down. (This can be seen in Figure 2 in the change in slope of the velocity-time graph and change in acceleration on the acceleration-time graph at approximately $2 \mathrm{sec}$., when the IOLab reached its highest point along the ramp.) This complicates initial learning of kinematics and Newton's laws. It is our opinion that the manufacturer should install bearings on the IOLab.

- The significant friction makes it more difficult to do the very effective RTP activities that directly lead to an understanding of Newton's first law. We struggled with this, and in the end had to use hanging masses to compensate for the friction.

- The level of noise in the electronic signals from the force sensor sometimes makes it difficult to see the desired experimental results.

- Because we wanted to make these labs low-cost, we provided each student with only one IOLab. In order to incorporate the research-validated Newton's third law collision and conservation of momentum activities from RTP into Lab 7 we incorporated videos of two lOLabs. ${ }^{22}$

- Like all accelerometers, the IOLab measures proper acceleration (acceleration relative to free-fall), not coordinate acceleration (acceleration with respect to the lab). This can cause conceptual difficulties for beginning students. We used accelerations calculated from the wheel encoder for this reason, and also because measurements from the encoder are pedagogically richer, since they explicitly include both velocity-time and acceleration-time graphs.

- Technical support for some distance-learning students proved to be challenging, especially at Chemeketa. Students had a variety of computer operating systems and hardware, and they had a wide range of computer skills. (For example, some lacked the ability to move files from one folder to another.) At Chemeketa, we posted instructions and videos showing how to install and use the software. We also used an online discussion board where students could post questions and screen captures when they encountered problems. At PSU, we met with students in person at the beginning of the term to issue equipment and install software. 
Even with considerable effort to help students, a few chose to drop rather than work to overcome these issues. But the overall dropout rate was comparable to regular classes at PSU and Chemeketa.

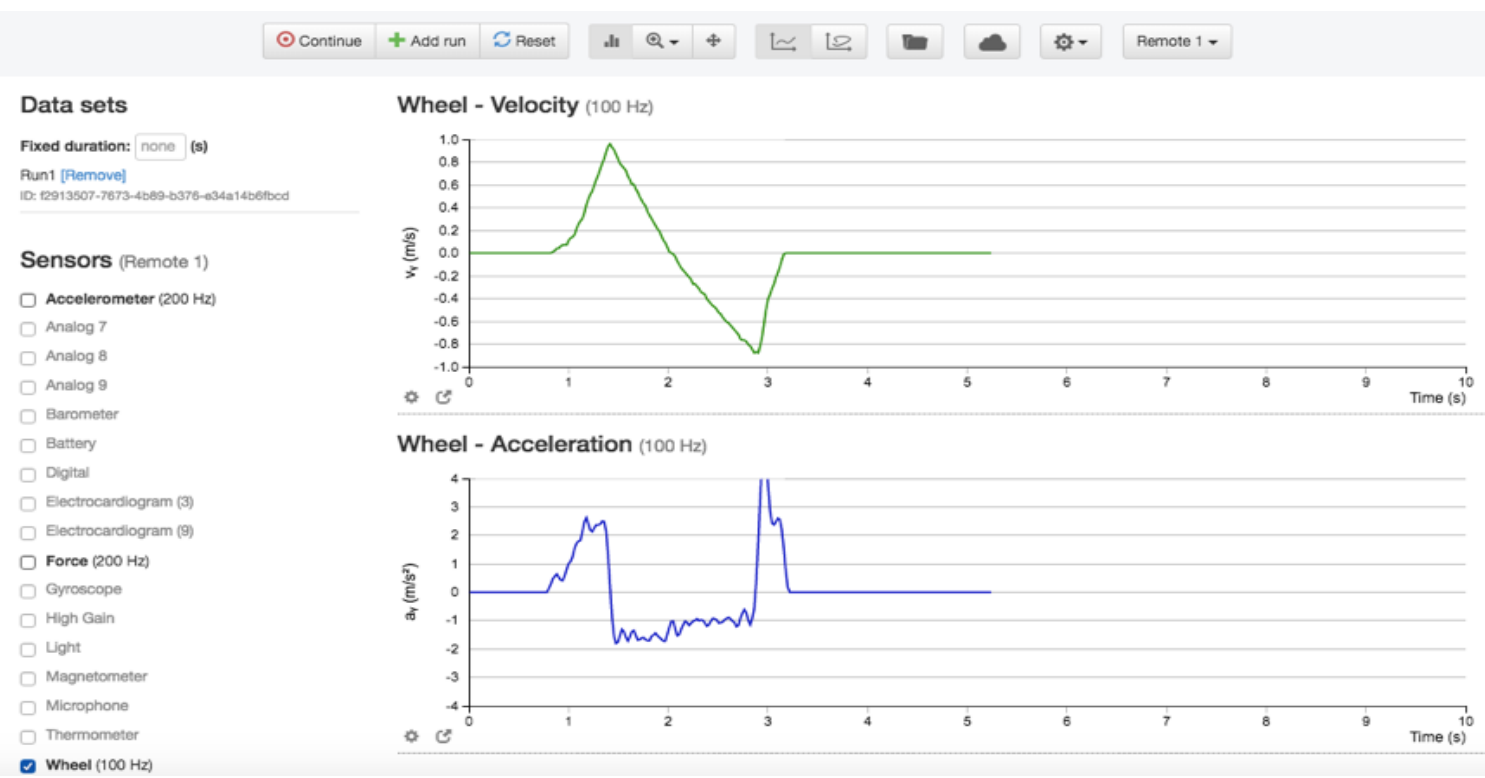

Figure 2. Graphs of velocity vs. time and acceleration vs. time collected by the IOLab encoder for motion up and back down a smooth inclined ramp.

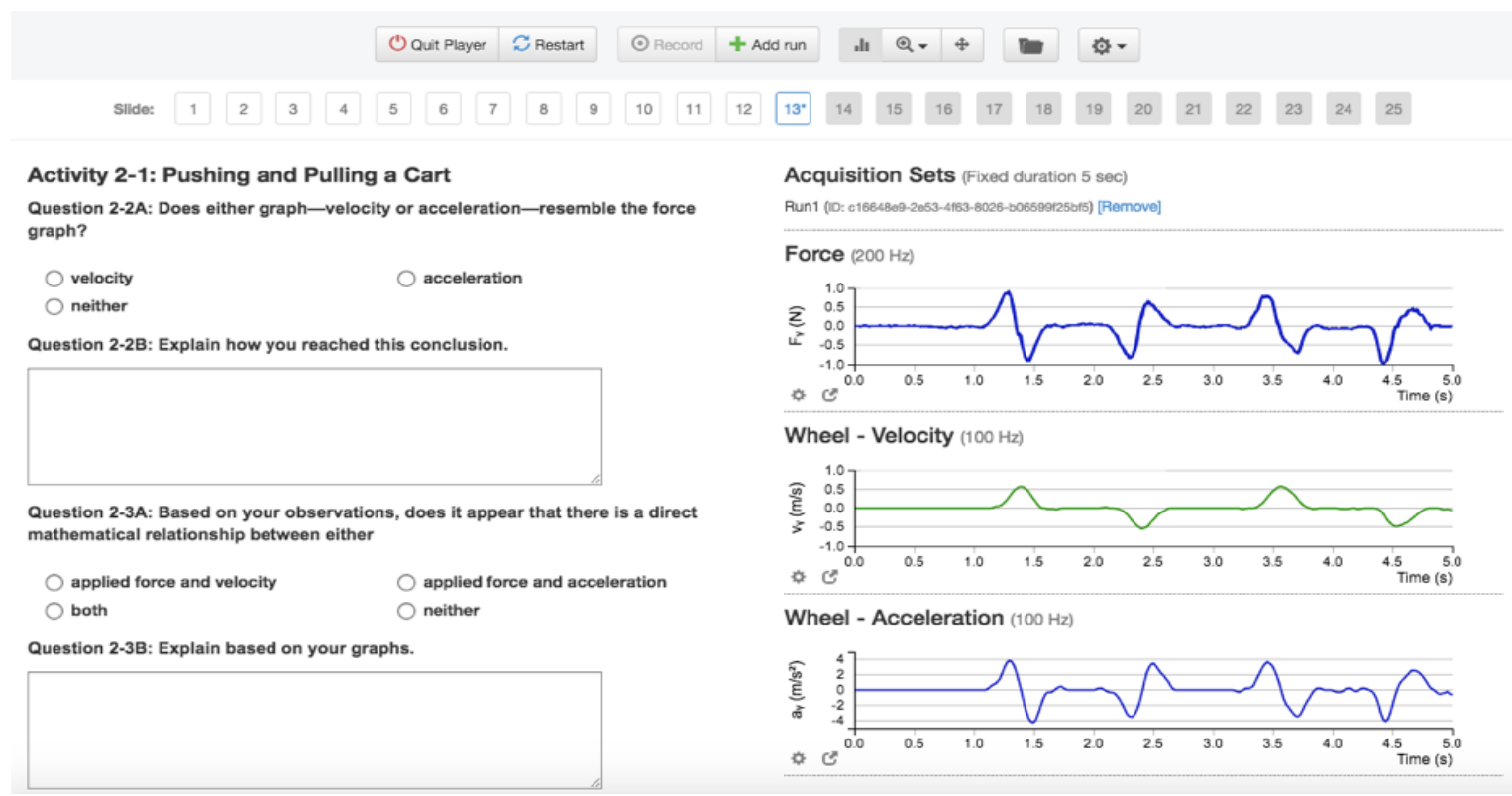

Figure 3. An example of the appearance of a slide from Lab 4 as displayed with Lesson Player. 
Table 1. Active Learning Labs in Mechanics Developed for Use with IOLab Lab 1 Introduction to IOLab

Lab 2 Introduction to Motion

Lab 3 Changing Motion

Lab 4 Force and Motion

Lab 5 More About Newton's Laws

Lab 6 Impulse and Momentum

Lab 7 Newton's 3rd Law and Conservation of Momentum

Lab 8 Two-Dimensional Motion

Lab 9 Work and Energy

\section{Conceptual learning as measured with the FMCE}

We measured learning of concepts related to kinematics and Newton's laws with a shortened (34 question) version of the Force and Motion Conceptual Evaluation (FMCE). ${ }^{23,24}$ Figure 4 compares the normalized gains ${ }^{25}$ for the most recent tests at both PSU and Chemeketa (fall, 2017), after several years of refining the labs (as described above).

The randomly assigned control group at $\mathrm{PSU}^{26}$ only completed the post-test. We calculated the normalized gain for this control group assuming that their pre-test score was the same as the average of the PSU IOLab group. (From previous rounds, we knew that the pretest scores do not differ substantially for the various groups at PSU.) The Chemeketa controls completed both the pre and post-test, and their normalized gains were calculated directly.

The conceptual learning gains by the IOLab groups are consistently significantly better than the control groups that did traditional labs. Note that all students at PSU were experiencing traditional lectures from several different lecturers whom the students selected randomly. Therefore, the higher learning gains for the IOLab groups can be attributed to their IOLab experience. The distance-learning students at Chemeketa experienced "lecture" material enhanced by active learning strategies ${ }^{15}$ which probably 
accounts for their somewhat higher overall learning gains. While these results are not as good as those achieved with $R T P,{ }^{8}$ we conclude that our adaptation of $R T P$ for the IOLab consistently and measurably improves student conceptual understanding for both distance-learning and campus-based students.

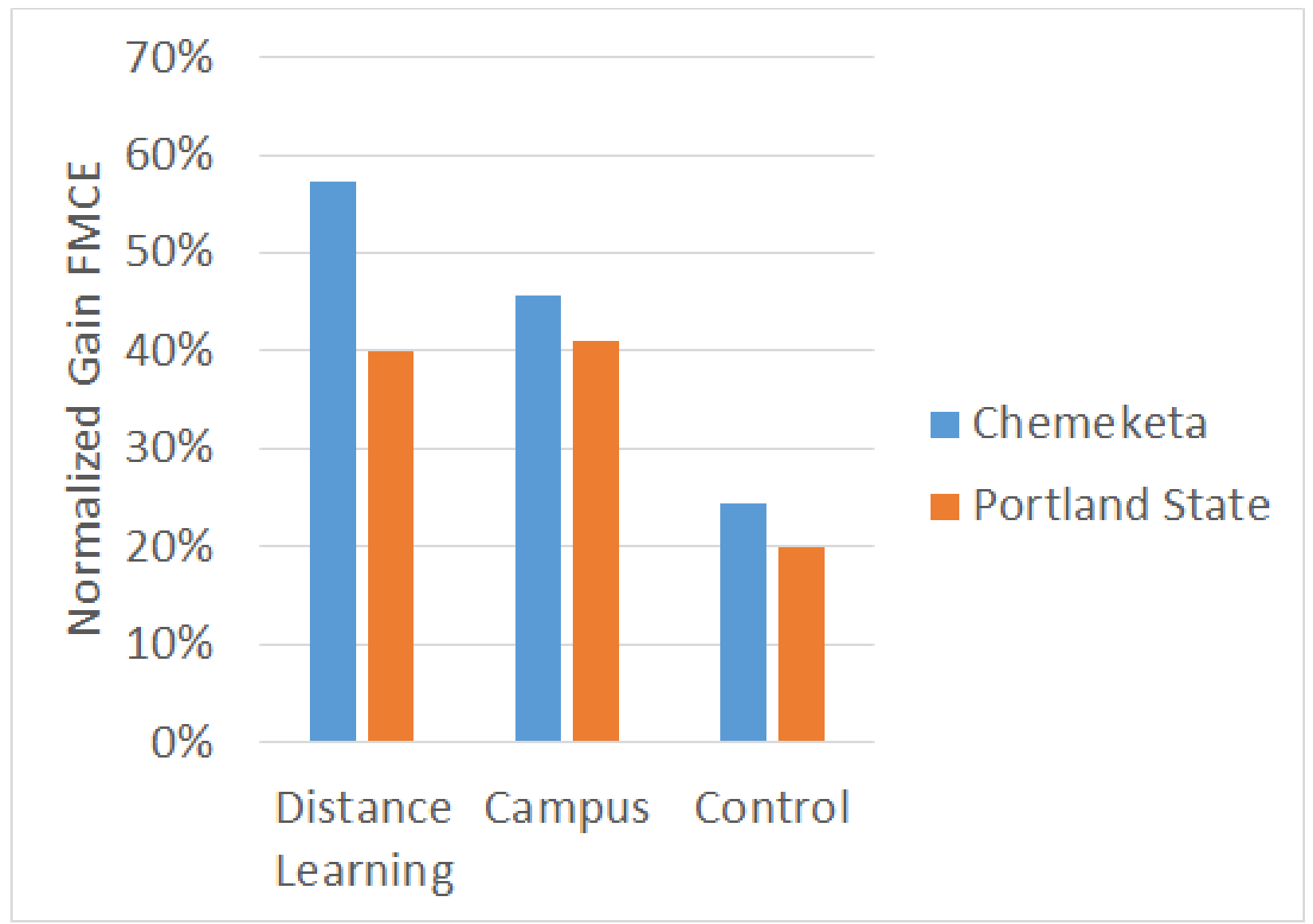

Figure 4. Normalized learning gains on the shortened, 34-question Force and Motion Conceptual Evaluation for students at Chemeketa and PSU during fall, 2017. Group sizes for Chemeketa were Distance $\mathrm{N}=30$, Campus $\mathrm{N}=26$, Control $\mathrm{N}=25$. For PSU, Distance $\mathrm{N}=41$, Campus $\mathrm{N}=33$, Control $\mathrm{N}=69$.

\section{Evaluation of student attitudes}

The students experiencing the labs, IOLab device, and IOLab software had generally favorable attitudes towards their experience, as indicated by their responses on end-ofterm lab course evaluations. For example, Table 2 shows the average response (5=strongly agree . . 1 1=strongly disagree) to a number of statements describing the experience of the PSU students who did the labs in distance-learning mode during fall, 2017. The ratings of statements 1 and 2 indicate that the students were comfortable 
carrying out the experiments on their own, at home, while statements 4-7 indicate a positive feeling about the learning environment established by these labs. The results on statement 3 (5=learned much more . . . 1=learned a lot less) indicate a generally positive perception of the learning experience with the IOLabs.

Although we did not set out to change attitudes towards experimental physics, we did check if any changes occurred. We had students respond to portions of the E-CLASS ${ }^{27}$ both pre and post in fall term, 2017. We did not find any change in student strategies, habits of mind, or attitudes towards experimental physics based on this metric. ${ }^{28}$

Table 2. Average response on end-of-term evaluations by distance students at PSU, fall, $2017, \mathrm{~N}=41$.

\begin{tabular}{|r|l|c|}
\hline 1 & $\begin{array}{l}\text { Knowing there are tens of very short YouTube videos online, explaining some of the } \\
\text { more confusing parts of using IOLab and software, I could have done these labs at } \\
\text { home. }\end{array}$ & 4.4 \\
\hline 2 & $\begin{array}{l}\text { Compare your perception of learning using this style of lab instructions to the lab } \\
\text { instructions you have used in other labs. }\end{array}$ & 3.6 \\
\hline 3 & These labs helped me with my conceptual understanding of physics. & 4.1 \\
\hline 4 & I have gained a greater insight into the nature of the physical world. & 4.2 \\
\hline 5 & I have learned useful concepts from the laboratory course. & 3.9 \\
\hline 6 & The laboratory course added to my understanding of the lectures. & 4.1 \\
\hline
\end{tabular}

\section{Implementation observations from the instructors}

From the instructor's perspective there are a number of advantages to the IOLab-based experiments:

- There were few conceptual questions from distance-learning students. When they contacted us it usually concerned a technical issue, not difficulty in understanding the physics. 
- The labs do a good job of connecting real-world experiences to mathematical representations.

- Grading is easier compared to standard labs. There is only one file for each lab, and all students submit essentially the same format file.

For campus-based labs:

- It is easier to demonstrate concepts to students with the IOLab equipment.

- Set up and tear down is much easier compared with most standard, traditional labs.

- There is less time needed to explain how the lab equipment works and, therefore, more time for student work and discussion.

- If students miss a class because of illness, etc., they can borrow an IOLab to make it up. (Of course, providing accommodations for excused absences is one big benefit of distance-learning classes, and in several instances made it possible for students to take the course.)

\section{Conclusions}

We have established that research-validated introductory physics labs can be delivered effectively in distance-learning mode at low cost using IOLab. While the goals of the introductory lab can certainly be debated, they should be both explicit and measurable. We consider conceptual learning in lab to be important and achievable, and we urge the physics education community to embrace active learning, research-validated labs. The labs we developed for use with the IOLab are a viable, inexpensive option.

\section{Acknowledgements}

We would like to thank Dr. Mats Selen and his colleagues at the University of Illinois and Dr. Geoffroy Piroux at B12 Consulting for development of the IOLab and software. We also thank Dr. Selen for providing IOLabs for our pilot studies, and for listening to the many suggestions we made for improving the IOLab software, and Dr. Piroux for rapidly implementing most of these suggestions. We thank Dr. Kathleen Harper for her guidance as our evaluator, the NSF for financial support of our work, John Wiley and Sons for their permission to adapt RTP, and MacMillan, the manufacturer and distributor of the IOLab. We also thank Chemeketa students Paul Ivanov, Nicholas Jones and Benjamin Steele and PSU teaching assistants Mike DeArmond and Caitlin Kepple, for their contributions to this project. 


\section{References}

1 Julia E. Seaman, I. Elaine Allen and Jeff Seaman, "Tracking distance education in the United States," https://onlinelearningsurvey.com/reports/gradeincrease .pdf, page 11

2 lbid. page 7

${ }^{3}$ See, for example "Panel votes against accreditor of for-profit colleges," https://usnews.com/news/business/articles/2016-06-23/big-accreditor-of-for-profitcolleges-could-lose-authority.

${ }^{4}$ A. M. Reagan, "Online Introductory Physics Labs: Status and Methods," J. Washington Acad. Sciences, Spring 2012, pp. 31-46

5 "AAPT Recommendations for the Undergraduate Physics Laboratory Curriculum," https://aapt.org/Resources/upload/LabGuidlinesDocument_EBendorsed_nov10.pdf ${ }^{6}$ Carl Wieman, and N. G. Holmes, "Measuring the impact of an instructional laboratory on the learning of introductory physics", Am. J. Phys. 83, 972 (2015).

${ }^{7}$ Natasha G. Holmes, and Carl E. Wieman, "Introductory physics labs: We can do better", Physics Today 71, 1, 38 (January 2018).

${ }^{8}$ David R. Sokoloff, Ronald K. Thornton and Priscilla W. Laws, "RealTime Physics:

Active Learning Labs Transforming the Introductory Laboratory," Eur. J. of Phys. 28

S83-S94 (2007).

9 IOLab Wireless Lab System, https://iolab.science

${ }^{10}$ See, for example, the Pasco Wireless Smart Cart

(https://www.pasco.com/prodCompare/smart-cart/index.cfm) and the Vernier Go Direct Sensor Cart (https://www.vernier.com/products/sensors/motion-encoders/gdx-cart-g/).

11 See https://www.thepocketlab.com/.

12 David R. Sokoloff, Ronald K. Thornton and Priscilla W. Laws, RealTime Physics:

Active Learning Laboratories, Module 1: Mechanics, Module 2: Heat and

Thermodynamics, Module 3: Electricity and Magnetism, and Module 4: Light and Optics, $3^{\text {rd }}$ ed., (John Wiley and Sons, Hoboken, NJ, 2011).

${ }^{13}$ Funded under U.S. National Science Foundation grant DUE - 1505086, July 1, 2015June 30, 2018.

${ }^{14}$ Stephen Kanim, Ximena C. Cid, "The demographics of physics education research," https://arxiv.org/abs/1710.02598.

15 "Best Colleges, US News, Portland State University," https://usnews.com/best-

colleges/portland-state-3216

${ }^{16}$ Cheryl P. Rose, "Student diversity a notable asset for Chemeketa Community College,"

https://blog.oregonlive.com/education_plus/2016/05/student_diversity_a_notable_as.ht $\mathrm{ml}$

17 Influences include E. Mazur (Peer Instruction), L. McDermott (Tutorials in Introductory Physics), R. Knight (Five Easy Lessons), and D. Pritchard (Mastering Physics). 
18 Erik Jensen, "Welcome to PH201-203 Online," https://sites.google.com/chemeketa.edu/erikjensen/ph201-203I

${ }^{19}$ Tracker, a free video analysis and modeling tool, https://physlets.org/tracker/

${ }^{20}$ Erik Jensen, "PH201-203 Lab Kits," http://faculty.chemeketa.edu/ejensen6/labkits.html

${ }^{21}$ Fall, 2015 at PSU, winter, 2016 at Chemeketa, summer and fall, 2016 at PSU and Chemeketa and summer and fall, 2017 at PSU and Chemeketa.

${ }_{22}$ See collision video example, https://youtube.com/watch?v=Z-7wRSi52a0.

${ }^{23}$ Ronald K. Thornton and David R. Sokoloff, "Assessing Student Learning of Newton's Laws: The Force and Motion Conceptual Evaluation and the Evaluation of Active Learning Laboratory and Lecture Curricula," Am. J. Phys. 66, 338-352 (1998).

${ }^{24}$ We shortened the FMCE in order to enlist the cooperation of those who were teaching the control groups. The version we used included questions 1-21, 30-38, and 40-43.

${ }^{25}$ Normalized gain $\langle\mathrm{g}\rangle$ is defined by $\langle g\rangle=100 \% x \frac{\text { (Post.score-Pre.score) }}{\text { (Max. possible score-Pre.score) }}$

${ }^{26}$ Students could opt out of either version of the lab as control groups were taught at the same times as the IOLab groups, but none chose to do so.

${ }^{27} \mathrm{H}$. Lewandowski, "E-CLASS: Colorado Learning Attitudes About Science Survey for Experimental Physics," https://jila.colorado.edu/lewandowski/research/e-class-coloradolearning-attitudes-about-science-survey-experimental-physics.

${ }^{28}$ Bethany R. Wilcox and H. J. Lewandowski, "Open-ended labs can be designed with gains on the E-CLASS as an explicit goal," Phys. Rev. Phys. Educ. Res. 12, 020132 (2016). 